\title{
Trauma, postmigrationsstress och suicidala tankar hos asylsökande
}

\author{
Ved Solvig Ekblad og Shervin Shahnavaz
}

\begin{abstract}
En screeningintervju av vuxna asylsökande kort efter ankomst till Sverige visar på betydelsen av att identifiera traumatiska erfarenheter och stressfaktorer såväl före som efter migrationen. Det är viktigt att uppmärksamma brott mot mänskliga rättigheter före ankomsten och dess samband med suicidala tankar. Studien belyser hur människor som lever i väntan på asyl är en sårbar grupp för suicidala tankar och annan psykosocial ohälsa vilket kan påverka asylsökandes trovärdighet. Symtompanorama, och individens behou samt önskemål leder till olika typer av kliniska interventioner. Fynden stödjer den psykiatriska forskning som visar att känsla av sammanhang är en viktig faktor att förutsäga suicid hos patienter. Tidiga, förebyggande individualiserade insatser för flyktingar, inklusive asylsökande som lider av själumordsnära beteenden och andra hälsorelaterade problem är en investering för alla.
\end{abstract}

\section{Bakgrund och syfte}

En översikt visar att det finns ett stort mörkertal av hur många asylsökande som har självmordsnära beteenden (Ekblad $\&$ W asserman 2002). En internationell översikt (Silove \& Ekblad 2002) avseende långtidsuppföljningar av flyktingars psykosociala an passning i värdlandet uppmärksammar två riskfaktorer för psykiska ohäl sa: (1) traumaupplevel ser före ankomst, och (2) postmigrationsstress i form av upplevelser till följd av mottagandet ( t ex kränkande särbehandling pă grund av etniskt ursprung, hot om avvisning under en långdragen asylprocess, sysslolöshet, kommunikationssvårigheter, och brist på social trygghet). Emellertid är det viktigt att komma ihåg att inte alla flyktingar och andra utrikesfödda är traumatiserade. Dessutom kan många som är traumatiserade genom s.k. självläkning undkomma de långsiktiga negativa konsekvenserna av trauma. I psykiatrisk forskning har känslan av sammanhang (A ntonovsky 1987) blivit uppmärksammad som en viktig faktor för att förutsäga självmord hos patienter (Petrie \& Brook 1992). I flyktingmottagandet handlar det om att så tidigt som möjligt upptäcka den grupp som mår psykiskt dåligt, speciellt dom som har suicidtankar och som upplever sig ha dålig funktionsförmåga och därför inte har en förmåga att kunna hantera sin situation.

Syftet med aktuell studie, som är en del av en större studie (Ekblad \& Shahnavaz 2002) var att upptäcka dimensioner på trauma och postmigrationsstress som hade samband med suicidala tankar och upplevd hälsa bland asylsökande kort efter ankomst till Sverige.

\section{Undersökningspopulation}

U ndersökningspopulationen bestod av alla asylsökande som var arabisk-, serbokratisk ( $\mathrm{skb}=$ serbiska, kroatiska och bosniska) - och persisktalande personer ( $23 \%, 63 \%$, respektive $14 \%)$ som anlände till flyktingmottagningsen heterna $\mathrm{H}$ ultsfred, Flen och Skärholmen under oktober 2001 - januari 2002. Sammanlagt fanns 246 personer på kallelselistan (asylsökande som kommit till Sverige någon gång under undersökningsperioden) och talade något av de tre språken. Å tta personer intervjuades först i en pilotstudie. Totalt genomfördes 92 intervjuer. Resten kom inte till informationsmötet och/eller var närvarande vid mötet men bokade inte tider eller uteblev. Vissa personer hade flyttat till andra orter i Sverige, utomlands eller till hemlandet efter avvisningsbeslut.

A v de 92 asylsökande var 63\% (58) män och $37 \%$ (34) kvinnor. M edelåldern var för män 34 år ( $S D=9.35)$ och för kvinnor 33 år (SD =8.73); ( min-max ålder: 20-56 år). Sex av tio var gifta, något högre andel bland kvinnor än bland män $(77 \%$ respektive $50 \%$ ) medan en tredjedel (flest män) var ensamstående. Resten, $6 \%$, uppgav övrigt civilstånd. I genomsnitt hade de intervjuade - både män och kvinnor - genomgått 12 års skol gång. H älften uppgav att de hade arbetat i hemlandet före ankomsten. D rygt hälften av de intervjuade, $63 \%$, kom från Bosnien, forna
Jugoslavien, Kroatien eller M akedonien. $N$ ågot över en femtedel, $23 \%$, kom från Irak, 10\% från I ran och 4\% från A fghanistan. $\mathrm{H}$ älften uppgav att de sökt asyl på grund av förföljelse: politiska skäl och resten av de intervjuade (47\%) nämnde "annat skäl". De flesta intervjuades på $\mathrm{H}$ ulftsfreds flyktingmottagningsenhet (55\%, 51 asylsökande) följt av Skärholmen/Stockholm (30\%, 28 asylsökande) och Flen (14\%, 13 asylsökande). En fjärdedel, $24 \%$, uppgav att deras boende var i hög grad påfrestande. De som bodde i eget boende i Skärholmen (36\%) upplevde påfrestningen som värst, följt av Flen (blandat boende) $(31 \%)$, och H ultsfred (enbart anläggningsboende) (16\%). Trefjärdedelar uppgav att de deltog $i$ organiserad verksamhet ( $\mathrm{H}$ ultsfred, $84 \%$; Skärholmen, 75\%; och Flen, 69\%). De flesta, $93 \%$, svarade att de upplevde att syssel sättningen var meningsfull men tidsanvändningen upplevdes inte alls som tillfredsställande av $28 \%$ av de intervjuade (Skärholmen, $57 \%$; Flen, 23\%; och Hultsfred, 14\%).

\section{Intervjuformulär}

Insamlingen av data genomfördes genom ett screening intervjuformulär som i stort bestod av kända och i forskningssammanhang ofta använda frågor med hög validitet och reliabilitet $i$ transkulturell psykologi och psykiatri.

Formulären innehöll:

1. A llmänna frågor om aktuellt och tidigare hälsotillstånd (inklusive frågor om sjukdomar, behandlingar och tandvårdsrelaterade frågor) samt levnadsvanor.

Delar av manus har presenterats:

1) på XXII IA SP kongressen i Stockholm, 10-14 september, 2003

2) i Ekblad, S., Shahnavaz, S. Trauma och post-migrationsstress bland asylsökande - Betydelse av tidig upptäckt av depressiva symtom genom hälsosamtal och förmedling av sjukvårdskontakt. M anus i del projektet "H älsosamtal som en rutinmässig metod för kartläggning av medicinska, psykologiska och sociala behov och strategier för hälsan bland asylsökande och vid behov uppföljning inom hälso- och sjukvården - ett nationellt och EU -perspektiv"; i projektet Hälsosamtal (ERF 141/2001), löptid 1 september 2001 - 31 augusti, 2002. Slutrapport av genomfört projekt med stöd från bl a den europeiska flyktingfonden, 24 november 2002.

3) genom videokonferens på The Second A nnual A ustralian Society of Islamic Psychology Conference, 20 ctober, 2003, Sydney, A ustralia, Ekblad, S. (presenter) and Shahnavaz, S (presenter) Disruption of Sense of C oherence during the uncertain waiting time for asylum in Sweden - trauma before arrival, postmigration stress and mental health consequences. 
2. För hälsan relevanta bakgrundsfrågor såsom ålder, civilstånd, utbildning, sysselsättning, socialt nätverk, migrationsorsak $\mathrm{mm}$.

\section{Flertalet av frågorna i Depressions-} skalan i H opkins Symptom C hecklist 25 ( M ollica m fl 1985) användesför att belysa symtom på nedstämdhet inklusive suicidala tankar under den senaste veckan.

4. För frågor kring traumatiska hän delser och kriterier på post traumatiskt stresssyndrom (ptsd) användes en kortfattad version av $\mathrm{H}$ arvard Trauma Q uestionnarie (HTQ) (M ollica m fl 1994). En svensk översättning som tagit hänsyn till "back translation method" (Lin dencrona, Johansson-Blight \& Ekblad 2002) användes. och som använts av första författaren i flera olika projekt och flyktinggrupper.

5. Frågor kring problem med bl.a. värk och smärta (inv-U LF 96)

6. En omarbetad version av skala för att mäta känslan av otrygghet (inv-U LF 96), sk. postmigrationsstress.

7. Frågor för att mäta känslan av sammanhang dvs. intervjudeltagarens känsla av hanterbarhet, meningsfullhet och begriplighet hämtades från en förenklad version av Kasam, där en fråga per faktor användes (A ntonovsky 1987, Lundberg \& N yström Peck 1995).

8. Intervjudeltagare tillfrågades om de önskade att kontakt vid behov förmedlades till sjukvården.

9. Tre utvärderingsfrågor som tidigare använts av förste författaren i olika projekt användes. Svarsalternativen var "ja" och "nej" till frågor om svårighetsgrad och relevans av frågorna samt om de kändes kränkande. Slutligen ställdes en öppen fråga om det var någon/några viktiga frågor som intervjuaren hade missat att ställa och i så fall vilken/vilka?

\section{Genomförande}

Intervjudeltagarna fick läsa skriftlig information om studien, som översatts och tillbakaöversatts till arabiska, persiska och serbokratiska (skb) - och tid bokades för intervju. Deltagan det var frivilligt. Intervjuerna genomfördes i Skärholmen av båda artikelförfattarna, i H ultsfred och i Flen av handläggare på M igrationsverket och under regelbunden handledning av bägge författarna. De persisktalande asylsökan de intervjuades på alla tre flyktingmottagningsenheterna av andre författaren som behärskade språket. Ö vriga intervjuer genomfördes genom tolk inklusive telefontolkning.

\section{Databearbetning och data analyser}

De insamlade formulären har inkodats och bearbetas i SPSS av båda författarna. Interreliabilitetskontroll av inmatningen resulterade i en felprocent strax under $1 \%$. Följande statistiska analyser har gjorts i denna del studie: frekvensfördelningar, totalt och uppdelat i förekommande fall på kön, chi-2 test, t-test, korrelationer (Spearman), faktor analys, principal komponent analys samt logistisk regressions beräkning. Reliabilitetstestning har utförts med C ronbach-alfa-koefficient.

\section{Resultat}

\section{Trauma och postmigrationsstress}

Över hälften av de asylsökande hade upplevt krig (91\%), förlust av nära och kära (70\%), sett våld mot andra (65\%), och drabbats materiellt (65\%). Fyra av tio uppgav att de varit utsatta för tortyr. Det var enbart kvinnor (6\%) som svarade på att de varit utsatta för våldtäckt och sexuella övergrepp. M ännen hade i signifikant större utsträckning sett våld mot

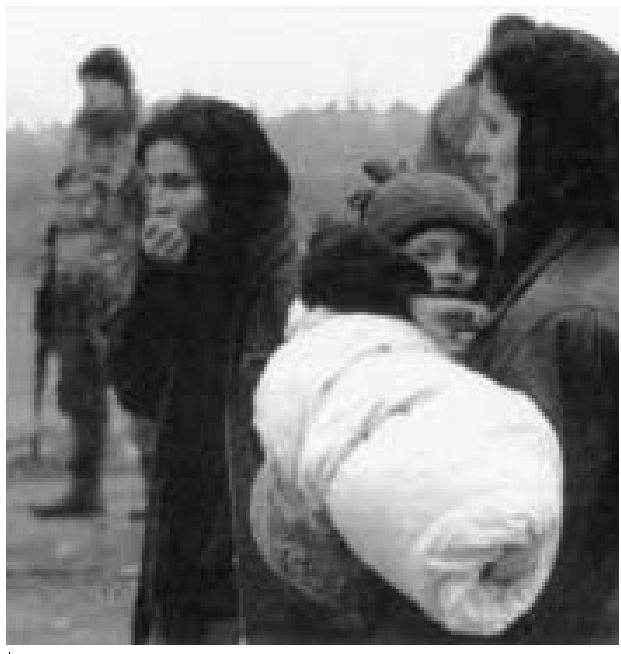

andra, varit utsatt för tortyr, upplevt fångenskap, våld mot huvudet och upplevt allvarlig kroppsskada (Tabell 1).

Drygt hälften (55\%) uppgav att de kände mycket stor otrygghet under den senaste veckan för att bli hemskickade. Siffran var något högre för kvinnorna än för männen. (kvinnor: $68 \%$, respektive män: $48 \%$, chi $\left.^{2}=3.26, d f=1, p<.071\right)$. Knappt hälften (45\%) kände mycket stor oro för sin familj, och en på fyra kände oro för både det internationella läget och sin ekonomi. En femtedel uppgav mycket stor oro för sin hälsa. Knappt hälften $(48 \%)$ svarade att de hade en riktigt nära vän som han eller hon kunde kontakta och prata om vad som helst med.

Tabell 1.

Traumatiska livshändelser före ankomst till Sverige. Procentvis fördelning

\begin{tabular}{|l|r|c|c|c|}
\hline Traumatiska livshändelser & Tot(\%) & M än(\%) & Kvinnor(\%) & Sign \\
\hline Drabbats materiellt & $58(65)$ & $38(67)$ & $20(63)$ & $n s$ \\
\hline U pplevt krig & $83(91)$ & $52(91)$ & $31(91)$ & $n s$ \\
\hline U pplevt allvarlig kroppsskada & $18(20)$ & $17(29)$ & $1(3)$ & $\mathrm{p}<.002$ \\
\hline Upplevt fångenskap & $31(34)$ & $27(47)$ & $4(12)$ & $\mathrm{p}<.001$ \\
\hline Varit utsatt för tortyr & $37(41)$ & $28(49)$ & $9(27)$ & $\mathrm{p}<.033$ \\
\hline T vungen att skada andra & $8(9)$ & $8(14)$ & - & $\mathrm{p}<.023$ \\
\hline Förlust av nära och kära & $64(70)$ & $41(72)$ & $23(68)$ & $\mathrm{ns}$ \\
\hline Sett våld på andra & $60(65)$ & $43(74)$ & $17(50)$ & $\mathrm{p}<.019$ \\
\hline Våld mot huvudet & $25(27)$ & $20(35)$ & $5(15)$ & $\mathrm{p}<.040$ \\
\hline Våldtäckt, sexuella övergrepp & $2(2)$ & - & $2(6)$ & $\mathrm{p}<.064$ \\
\hline
\end{tabular}




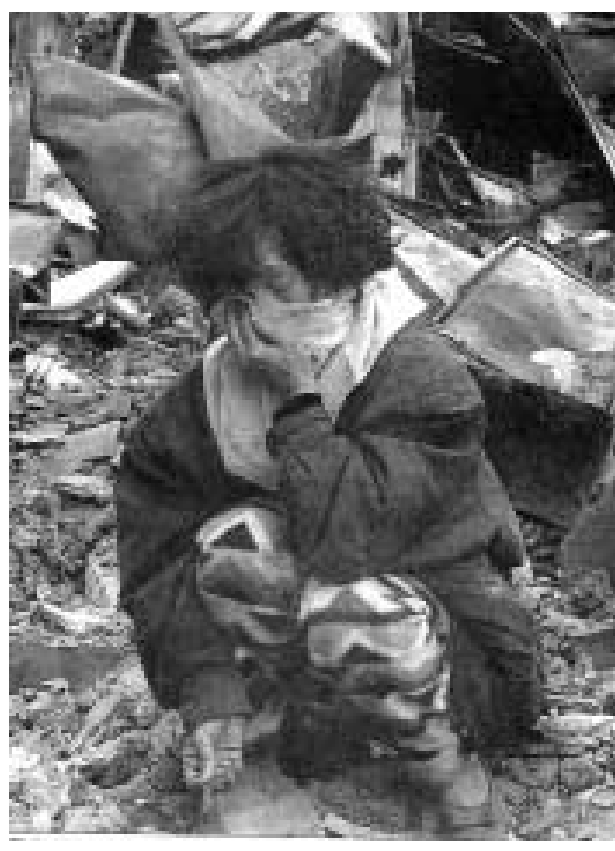

En principal komponent analys av de 10 traumatiska upplevel serna resulterade i tre dimensioner: Den första dimensionen, brott mot mänskliga rättigheter, bestod av våld och tortyr mot kropp inklusive huvud, den andra dimensionen, materiellt drabbad och sett våld mot familjemedlemmar, inkluderade att ha blivit materiellt drabbad och sett våld mot anhöriga i samband med krig, och den tredje dimensionen, tvingad till isolering och skada, stod för fångenskap och övergrepp. Dessa tre dimensioner utgjorde $54 \%$ av den totala variansen (25\%, $15 \%$ och $14 \%$ ). Intern konsistens var relativt hög 0.66 ( C ronbach-al pha-koefficient). M än hade jämfört med kvinnor

Tabell 2. signifikant högre värden på den första dimension (0.005) och den tredje dimensionen (0.001).

$\mathrm{N}$ io postmigrations-stressfaktorer utmynnade i en principal komponent analys i tre dimensioner: (1) behov kopplade till överlevnad, (2) internationell och nationell politisk instabilitet, och (3) risk för allvarliga infektioner och diskriminering. Dessa tre dimensioner utgjorde $56 \%$ av den totala variansen $(23 \%, 17 \%$, och $16 \%)$. Intern konsistens var relativt hög 0.68 (C ronbach-alpha-koefficient). Det förekom inga signifikanta könsskillnader.

\section{Suicidtankar}

Drygt en femtedel (23\%) svarade ja på frågan "H ar du haft tankar kring att ta Ditt liv?" (med svarsalternativ "inte alls" (1), "lite" (2), "en hel del" (3) och "väldigt mycket" (4)) under den sista veckan, varav fem procent av de intervjuade kände väldigt mycket av dessa självmordstankar.

Det var en positiv korrelation mellan suicidala tankar, posttraumatiska stress symtom $(0.270, p<0.009)$ och depressiva symtom $(0.699, p<0.0001)$ och en negativ korrelation med känsla av sammanhang $(-0.258, p<0.013)$.

En logistisk regressionsanalys av dimensionerna från de tio traumatiska livshändelserna före ankomst till Sverige och de nio postmigrationsstress frågorna resulterade i att en av de traumatiska livshändelserna, att erfara brott mot de mänskliga rättigheterna, dubblerade risken för suicidala tankar (Tabell 2).

\section{Diskussion}

B ortfallet och mätmetodernas relevans

Det använda intervjuformuläret visade sig i huvudsak vara lämpat för ändamålet och det var klart relevant att ställa frågor om tidigare trauman före ankomst och postmigrationsstress i mottagandet under väntan på asyl. En tredjedel (32\%) svarade att de upplevde att frågorna var svåra att besvara. I stort sett alla svarade att frågorna upplevdes rel evanta (99\%) och inte kränkande ( $98 \%)$. M en för att reducera bortfallet i en liknande framtida studie är det viktigt att diskutera hur asylsökande kan motiveras att delta i hälsosamtal och screening. På grund av praktiska svårigheter kunde vi inte undersöka orsaken till att så många inte kunde intervjuas. Emellertid ger W eisaeth (1989) i en studie från en industrikatastrof en möjlig förklaring i det att människor som visar motstånd mot hälsoundersökning efter en katastrof är överrepresenterade bland dem som senare utvecklar diagnosen PTSD.

$\mathrm{N}$ ågra andra begränsningar för studien var brist på begreppsekvivalens mellan de fyra språken (svenska, arabiska, persiska och serbokratiska, skb) när det gäller skalor och normer, att antalet deltagare i studien var relativt litet, att det var frivilligt att delta, och att resultaten står för hur den asyl sökan de upplevde sin situation under den senaste veckan. Det ettåriga projektet var alltför kort tidsmässigt för att man skulle kunna utvärdera utfallet för dem som rekommenderades uppföljning i sjukvården. Därtill var vårdresurserna olika för de tre flyktingmottagnings-

\section{Logistisk regressionsanalys av riskfaktorer för suicidala tankar}

\begin{tabular}{|l|c|c|c|}
\hline \multirow{2}{*}{ R iskfaktorer } & \multicolumn{3}{|c}{ Suicidala tankar } \\
Odds ratio (OR) & Konfidensintervall & p-värde \\
\hline Trauma före ankomst & & & \\
\hline Brott mot mänskliga rättigheter (tortyr) & 1,912 & $1,060-3,449$ & 0,031 \\
\hline M ateriellt drabbad och sett våld mot familjen & 1,065 & $0,578-1,961$ & 0,840 \\
\hline T vingad till isolering och skada & 0,710 & $0,422-1,193$ & 0,196 \\
\hline Postmigrationsstress & & & \\
\hline Behov kopplade till överlevnad & 1,413 & $0,741-2,695$ & 0,294 \\
\hline Internationell och, nationellt politisk instabilitet & 1,246 & $0,644-2,413$ & 0,514 \\
\hline Risk för allvarliga infektioner och diskriminering & 0,672 & $0,325-1,391$ & 0,284 \\
\hline
\end{tabular}


enheterna. Vi rekommenderade alla som hade höga poäng på depression- och/eller ptsd-skal orna att ta kontakt med sjukvården. De fynd som presenterades ovan behöver nyanseras mer i en framtida prospektiv studie, men aktuell studie har emellertid ett antal värdefulla resultat som diskuteras nedan.

\section{B rott mot mänskliga rättigheter, en riskfaktor för suicidtankar}

Sambanden mellan traumatiska erfarenheter före migration, speciellt tortyr, postmigrationsstress och PT SD, har dokumenterats i studier med olika invandrargrupper (för en översikt se Steel $\mathrm{m}$ fl 2002 och H ollifield $\mathrm{m}$ fl 2002). Ett generellt hot, brott mot mänskliga rättigheter före ankomst är den dimension som framstår som klarast och som därför behöver uppmärksammas vid erbjudan det om hälsoundersökning och hälsosamtal av alla asylsökande. Enligt Landstingsförbundet (2003) genomfördes initial hälsoundersökning av nyanlända de facto endast ca en tredjedel av de asylsökan de under 2002, vilket försvagar bilden av dessa personers vård- och stödbehov. För asylsökande kan symtomen, förutom psykiskt lidande och risk för självmord (Ekblad \& W asserman 2002) innebära sämre möjlighet att erhålla uppehållstillstånd. Forskning visar att PT SD genom sin effekt på minnesfunktioner kan påverka asylsökandes trovärdighet. M an menar att i samband med asylprövningen finns det en risk att asylsökande med PTSD nekas uppehållstillstånd ju längre tiden går mellan intervjuerna för asylprövning (Herlihy $\mathrm{m}$ fl 2002).

PT SD är trots dessa fynd en kritiserad diagnos. Kritikerna menar bl a att effekterna av traumata är överbetonade, att diagnosen PT SD riskerar att stigmatisera flyktingars erfarenheter av att reagera på extrema händelser, och att psykiatrisk rådgivning och behandling är främmande för flyktingar från icke-västerländska kulturer. A ktuell studie bekräftar emellertid förekomsten av ptsd symtom hos en stor andel av studiedeltagarna (52\%) men studien visar också på en ännu inte tillräckligt uppmärksammat samband, nämligen betydel sen av postmigrationsstress för de depressiva symtomen, suicidtankar och sänkt funktionsförmåga. Resultatet av denna studie har betydel se för vilka symtom som fokuseras vid hälsosamtal för asylsökande samt de behandlingsinterventioner som hälsosamtalet leder till.

\section{Skyddsmekanismer}

Det råder oklarheter om vilka skyddsmekanismer som är verksamma över tid vid flyktingtrauma. N är det gäller skyddsmekanismer för psykisk ohälsa visar litteraturen att det finns flera samvarierande faktorer. A ntonovskys (1987) meningsskapande sammanhang, att vara mentalt förberedd och att ha upplevelsen av att kunna kontrollera sin livssituation tycks ha betydelse för t ex tortyröverlevande (Basoglu $\mathrm{m}$ fl 1997, Ekblad \& W ennström 1997). I aktuell studie finns ett negativt samband mellan känsla av sammanhang och kriterier på ptsd, depressiva symtom och värk. Dessa fynd stödjer den psykiatriska forskning som visar att känsla av sammanhang är en viktigt faktor att förutsäga suicid hos patienter ( $M$ ehlum 1998, Petrie \& Brook 1992, Ekblad \& Shahnavaz 2003).

A ktuell studie visar att en hälsointervju kan identifiera asylsökande som av häl soskäl, som framför allt har suicidtankar, inte kan delta i vanlig organiserad verksamhet. D essa borde då erbjudas en mer meningsfull och stödjande sysselsättning och med handledning till personal.

\section{M ålstyrning och samverkan}

Ett framgångsrikt hälsoarbete kräver en målstyrning av verksamheten och ett hållbart partnerskap mellan olika inblandade lokala aktörer (inklusive FoU ) för uppföljning av hälsofrämjande åtgärder samt utbildning av handläggare i mottagandet och för sjukvårdspersonal. Teoriansatsen bör vara en socialekologisk, multifaktoriell och kontextuell (Lindencrona $m$ fl 2002) modell för hur de olika sociala, psykiska och medicinska faktorerna samverkar.

\section{A cknowledgement}

Forskningsprojektet "H älsosamtal för asylsökande. M etodutveckling för tidig upptäckt av hälsorelaterade problem hos asylsökande samt förmedl ing till sjukvårdskontakt" som genomförts under perioden 2001-09-01 - 2002-08-31 vid Karolinska Institutet, Stockholm (KI dnr 3341/2001) har finansierats av Europeiska flyktingfonden (ERF 141/2001) och med delfinansiering i form av personal resurser från
M igrationsverket och Institutet för Psykosocial M edicin (IPM), Solna. Projektet har godkänts av Karolinska Institutets regionala forskningsetikkommitté ( $\mathrm{K}$ I Dnr 01-499). Denna studie genomfördes i samarbete med M igrationsverkets huvudkontor och dess handläggare vid flyktingmottagningsenheterna i H ultsfred, Flen och Stockholm. Ett stort tack till Solveig Bengtsson, H ultsfred som var kontaktperson för övriga handläggare; Kirstie K ungsmark och K las Larsson, Flen; Birgitta Torstensson, H ultsfred; Per Karlsson, Skärholmen, samt tolkar och deltagare.

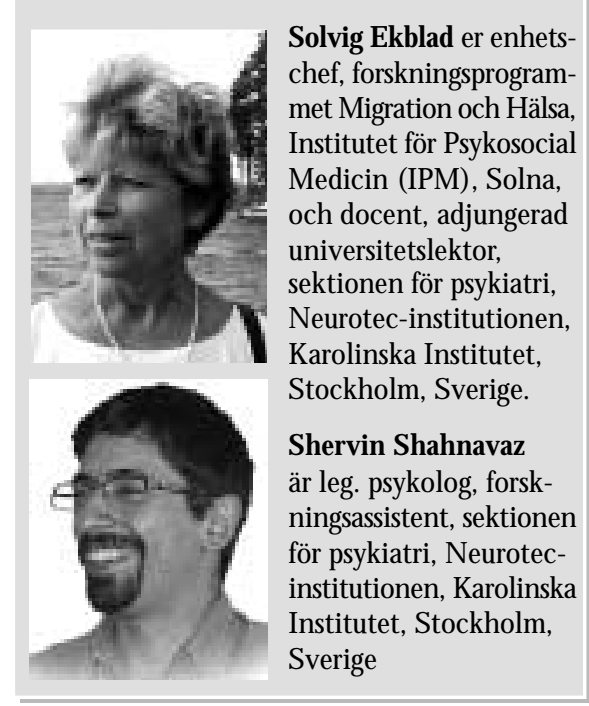

Korresponderande författares e-postadress och fax: e-postadress: Solvig.Ekblad@ipm.ki.se shvz@privat.utfors.se Fax: +468 330652

\section{Referenser}

A ntonovsky A. U nravelling the mystery of health. H ow people manage stress and stay well.

San Francisco: Jossey Bass, 1987.

Basoglu M, M ineka S, Paker M, A ker T, Livanou $M$, G ök S. Psychological preparedness for trauma as a protective factor in survivors of torture. Psychological M edicine 1997; 27 :1421-433.

Ekblad S, W asserman D. (red): Tidig upptäckt och preventiv behandling av asylsökande i riskzonen för självmord. Stockholm: Institutet för Psykosocial M edicin (IPM), Avdelningen för stressforskning, Karolinska Institutet, W H O :s Psykosociala center, 2002. (Stressforskningsrapport nr 307 - 2002)

Ekblad S, W ennström C. R elationships between traumatic life events, symptoms and Sense of C oherence subscale M eaningfulness in a group of refugee and immigrant patients referred to a Stockholm psychiatric out-patients clinic.

Scandinavian Journal of Social Welfare 1997; 6: 279-285. 


\section{SUICIDOLOGI 2004, ÅRG. 9, NR. 1}

(Forts. fra s. 22 - Ekblad och Shahnavaz)

Herlihy J, Scragg P, Turner S. Discrepancies in autobiographical memories-implications for the assessment of asylum seekers: repeated interviews study. British Medical Journal 2002; 324: 324-7.

Hollifield M, Warner TD, Lian N, Krakow B, Jenkins JH, Kesler J, Stevenson J, Westermeyer J. Measuring trauma and health status in refugees. A critical review. JAMA 2002; 288(5): 611-621.

Landstingsförbundet. (2003). Sjukvård åt asylsökande, omfattning och kostnader under år 2002. PM 2003-06-10

Lindencrona F, Johansson Blight K, Ekblad S. Teori och val av metod för att studera hälsofrämjande insatser ur ett transkulturellt perspektiv. Nordisk Psykologi 2002; 54(1): 7-26.

Lundberg O., Nyström Peck, M. A simplified way of measuring sense of coherence. Experiences from a population survey in Sweden. European Journal of Public Health 1995; 5(1): 56-59.

Mehlum L. Suicidal ideation and sense of coherence in male conscripts. Acta Psychiatr Scand 1998: 98 (6): 487-92.

Mollica RF, Wyshak G, de Marneffe D, Tu B, Yang T, Khuon, F, Coelho R, Lavelle L. Hopkins Symptom Checklist - 25 Manual. Cambodian, Laotian and Vietnamese versions. Harvard School for Public Health, 1985.

Mollica RF, Caspi-Yavin Y, Lavelle J, Tor S, Yang T, Chan S, Pham T, Ryan A, de Marneffe D. The Harvard Trauma Questionnaire (HTQ). Manual for use with Cambodian, Lao and Vietnamese versions. Harvard Program in Refugee Trauma, Harvard School of Public Health, 1994.

Petrie K, Brook R. Sense of coherence, self esteem, depression and hopelessness as correlates of reattempting suicide. British Journal of Clinical Psychology 1992: 31: 293-300.

Silove D, Ekblad S. (red) How well do refugees adapt after resettlement in Western countries? Acta Psychiatrica Scandinavia 2002; 106: 401-402.

Steel Z, Silove D, Phan T, Bauman A. Long-term effect of psychological trauma on the mental health of Vietnamese refugees resettled in Australia: a population-based study. The Lancet 2002: 360: 1056-1062.

Weisæth L. A study of behavioural responses to an industrial disaster. Acta Psychiatr Scand 1989 ; 80 (Suppl. 355): 38-49. 